\title{
A paixão pela natureza e a busca pelo reencantamento do mundo: as paisagens de Fagundes Varela e Sousândrade
}

\author{
Regina Célia dos Santos Alves \\ Universidade Estadual de Londrina (UEL), Londrina, Paraná, Brasil \\ reginacsalves@hotmail.com
}

DOI: http://dx.doi.org/10.21165/el.v46i3.1647

\begin{abstract}
Resumo
Este trabalho tem por objetivo a análise do poema "As selvas", de Fagundes Varela, do livro Vozes da América, e do poema "Inverno", de Sousândrade, de Harpas Selvagens. Em meados do século XIX, em pleno Romantismo, os dois autores criam uma paisagem natural em um sentido particular. Considerando paisagem como a percepção de um espaço, é possível ver nos poemas mencionados uma concepção romântica que procura na natureza tropical não somente um aprazível e privilegiado espaço para se viver, mas uma espécie de "casa ontológica", de "terra natal" do ser. Nesse sentido, a paisagem construída por meio de um ponto de vista ideal, do qual se acerca o Romantismo, ultrapassa questões de ordem nacionalista, comuns à época e, de outra maneira, representa o desejo de encontrar e de criar um lugar utópico e aconchegante, onde tudo é mágico e o homem pode encontrar-se a si mesmo.
\end{abstract}

Palavras-chave: Fagundes Varela; Sousândrade; paisagem; reencantamento do mundo.

The passion for nature and the search for the world re-enchantment: the landscape of Fagundes Varela and Sousândrade

\begin{abstract}
This paper aims to analyze a poem by Fagundes Varela, "As selvas", from the book Vozes da América, and another by Sousândrade, "Inverno", from Harpas Selvagens. In the middle of the XIX century, in Romanticism, the two writers create natural landscape in a particular direction. Considering landscape as a perception of a space, it is possible to see in these poems a romantic conception that searches in tropical nature not only a great and privileged natural place to live, but also a kind of "ontological home", a "homeland" of the being. In that way, the landscape built through ideal romantic point of view goes beyond the approach of nationalist issues, common in that period, and, on the other hand, it represents the desire to find and to create utopia where everything is magic and where the man finds himself.
\end{abstract}

Keywords: Fagundes Varela; Sousândrade; landscape: world re-enchantment.

As árvores, os arbustos e as plantas são adereço e a vestimenta da terra. Não existe nada mais triste que o aspecto de um campo nu e vazio que oferece aos olhos apenas pedras, limo e areia. Revivificada pela natureza e coberta com seu vestido de núpcias em meio ao curso das águas e ao canto dos pássaros, a terra oferece ao homem, com a harmonia dos três reinos, um espetáculo cheio de vida, de interesse e de encanto, o único espetáculo no mundo que nunca cansa seus olhos e seu coração. (Jean-Jacques Rousseau, Os devaneios do caminhante solitário, 2008, p. 89) 


\section{O Romantismo e a figuração da paisagem}

Fagundes Varela (1841-1875) e Joaquim de Sousa Andrade (1832-1902), ou melhor, Sousândrade, como preferia o poeta, são dois casos interessantes de escritores românticos brasileiros marcados pelo esquecimento e pelo lugar marginal ocupado na historiografia literária. Contemporâneos, ambos viveram intensamente o espírito romântico de seu tempo, sobretudo no sentimento de desajuste diante do mundo, presente na trajetória individual e literária dos dois escritores, guardadas, obviamente, as diferenças marcantes que distam um fazer literário do outro.

Todavia, mesmo porque Varela e Sousândrade encontram-se acercados de uma sensibilidade romântica que, ora mais, ora menos, se manifesta em suas poesias, a paixão pela natureza é algo revelador em ambos e colabora para a criação de paisagens particulares, construídas como um complexo simbólico, imagens do próprio eu e de seus desejos e buscas.

De acordo com Michel Collot, no horizonte romântico, a paisagem encontra-se no centro da sensibilidade do sujeito, sendo a expressão de um estado de espírito: "Para que uma paisagem possa ser considerada 'romântica' é necessário uma certa continuidade entre o imaginário e a realidade, entre o interior e o exterior [...] 'uma paisagem qualquer é um estado de espírito"” (COLLOT, 2005, p. 43, tradução livre). ${ }^{1}$

De início, é preciso ter em mente que o termo paisagem, no sentido com o qual trabalharemos, refere-se à percepção de um determinado espaço e não a um espaço em si. Sendo assim, para a leitura da paisagem é fundamental considerar, em primeira instância, o sujeito, o ponto de vista que percebe, pois, como afirma Michel Collot, "a paisagem é espaço percebido, ligado a um ponto de vista: é uma extensão de uma região [de um país] que se oferece ao olhar de um observador" (2013, p. 17).

Embora Collot (2013) chame a atenção para o olhar quando menciona a natureza perceptiva da paisagem, é preciso lembrar que a percepção não se limita à visão, mas se estende a todos os outros sentidos que colaboram para a formação dessa imagem de um determinado lugar, que é a paisagem.

Desse modo, falar em paisagem, como observa Collot, é jamais abandonar o fato de que ela se constitui como uma unidade complexa, só existindo a partir da relação indissociável de três componentes básicos: um lugar, um olhar (não apenas o olhar, mas também a atuação de outros órgãos sensoriais) e uma imagem (COLLOT, 2013, p. 17). Portanto, é da fusão desses três elementos que se tem a concepção de paisagem conforme vem sendo entendida nos últimos anos em diferentes áreas, não obstante as particularidades de cada uma, como a geografia cultural, a filosofia e os estudos literários, por exemplo.

Ainda que objeto de exploração de longa data no campo artístico ${ }^{2}$, no período romântico, final do século XVIII até meados do século XIX na Europa - a paisagem se torna objeto de primeira ordem na literatura desse período. O Romantismo, como é sabido, implica uma nova sensibilidade em face das coisas e do mundo, especialmente uma postura avessa à modernidade e ao capitalismo, os quais se revelam aos olhos do

\footnotetext{
${ }^{1}$ Qu'un paysage puisse être dit “romantique” suppose une certaine continuité entre l'imaginaire et la réalité, l'intérieur et l'extérieur. [...] Un paysage quelconque est un état de l'âme. (COLLOT, 2005, p. 43).

${ }^{2}$ No mundo ocidental a paisagem surge vinculada à pintura, no Renascimento, mas no Oriente está presente há mais de um milênio antes, como mostra Augustin Berque, em El pensamiento paisajero.
} 
homem romântico como um universo onde impera a crise, a certeza da fragmentação do sujeito e de tudo o que se encontra a seu redor.

Partindo da ideia de Weltansanschauung (visão de mundo), Michel Löwy e Robert Sayre (1995, p. 34) consideram o romantismo "uma crítica da modernidade, isto é, da civilização capitalista moderna, em nome de valores e ideais do passado (pré-capitalista, pré-moderno)". Nesse sentido, existiria na atitude romântica, ainda segundo Löwy e Sayre, um impulso anticapitalista e antiburguês, responsável pela busca, não raro desesperada do romântico, de um mundo ideal, onde as perdas sentidas com o avanço da modernidade não se fizessem presentes.

Essa atitude leva o romântico à busca nostálgica pelo passado - idealmente concebido como melhor e mais verdadeiro que o presente - ou mesmo por um futuro utópico, de toda maneira também oposto aos valores que regem a sociedade capitalista. Mesmo quando permanece no seio da sociedade burguesa, almeja a transformação dessa realidade, atitude que pode tomar diferentes formas, como mostra Michel Löwy e Robert Sayre (1995, p. 43):

Tal atitude pode tomar a forma do dandismo ou esteticismo [...] da criação de uma comunidade de almas fraternas [...] de uma experiência utópica [...] ou, muito simplesmente, da paixão amorosa. [...] Enfim, é possível igualmente procurar o ideal na esfera da infância [...] No entanto, é possível também fugirmos da sociedade burguesa, abandonando as cidades pela via do campo e os países "modernos" pelos "exóticos", abandonando os centros de desenvolvimento capitalista para nos dirigirmos em direção de um "alhures" qualquer que conserve, no presente, um passado mais primitivo.

Sobretudo essa última via mencionada por Löwy e Sayre, a de abandono do mundo urbano e de busca do campo como espaço mais aprazível e autêntico, interessanos aqui mais de perto na leitura que pretendemos da paisagem nos poemas de Fagundes Varela e Sousândrade. Neles, a tônica recai exatamente sobre a procura do campo enquanto recanto harmônico, ao contrário da cidade, ambiente em todos os sentidos amedrontador.

Como é de conhecimento, a paisagem vai ser largamente explorada na literatura romântica, que a concebe como expressão do estado d'alma do sujeito. De acordo com Collot (2013, p. 82), "a correspondência que o Romantismo instaura entre a paisagem e o estado d'alma tem sentido duplo: supõe não somente a projeção da afetividade sobre o mundo, mas também a repercussão deste sobre a consciência do sujeito", como mostra na fala de Stendhal: "As paisagens eram como que um arco que brincavam com a minha alma" (COLLOT, 2013, p. 82).

Dessa perspectiva, a forma como o romântico significa a paisagem e a representa permite observar o tipo de relação que se estabelece entre o homem e o mundo, em todo sentido, aberta à nova sensibilidade trazida pelo Romantismo, qual seja, a da relação afetiva com o mundo. Sendo assim, "a paisagem, investida de afetividade e imaginação, interioriza-se totalmente" (COLLOT, 2013, p. 66).

A paisagem no Romantismo, portanto, está longe de funcionar como um simples espaço de enquadramento, um mero cenário. Nela, é possível observar aquilo que Augustin Berque (2009) chama de trajecção, e que consiste, grosso modo, no percurso que vai do sujeito ao objeto e vice-versa na criação de algo novo, ímpar. 
Para Collot (2013, p. 82), "o fato de uma paisagem ser "romântica" supõe uma certa continuidade entre o imaginário e a realidade, o interior e o exterior" e nela se "instaura uma 'relação desconhecida', emocional e espiritual, entre o homem e a natureza" (p. 70-71), o que afasta "qualquer pretensão à objetividade em favor de uma expressão de uma verdade intensamente subjetiva" (p. 71).

Com relação a Fagundes Varela e Sousândrade, é possível dizer que esse conceito e configuração da paisagem estão plenamente conformados em suas poesias. Se a paisagem faz referência a um lugar almejado ou não, mais que isso ela vale pelo que representa enquanto um posicionamento afetivo do eu frente ao mundo e não propriamente pela referência a um lugar em si.

\section{Fagundes Varela: a natureza enquanto casa, abrigo}

Fagundes Varela surge no cenário da poesia nacional na década de 60 do século XIX. Embora tenha gozado de prestígio em seu tempo e possa ser considerado um escritor importante, "o único nome de relevo da poesia da década de 60", como afirma Alfredo Bosi (1994, p. 18), ou aquele que possui momentos poéticos que permitem situá-lo "no nível do que de melhor se produziu nas letras brasileiras do século XIX", como defende Antonio Carlos Secchin (2005, p. 09), normalmente Varela é tido como um poeta menor no quadro da literatura brasileira, seja porque, como mostra Bosi, aparece tardiamente, após autores importantes como Gonçalves Dias, Álvares de Azevedo e Casimiro de Abreu, sendo deles tributário; seja porque antecede, inclusive com algumas preocupações temáticas (ardor nacionalista, o mito da América-paraíso, o negro) Castro Alves, que surgiria somente na década seguinte (BOSI, 1994, p. 119).

Esse lugar intermediário em relação a tendências marcantes do Romantismo no Brasil parece ter contribuído, de certa maneira, para o menor prestígio do escritor frente a outros contemporâneos seus, que alcançaram maior destaque, embora, como afirma Antonio Candido, não seja possível ver em Varela "um caso fácil de psicologia literária' (1981, p. 257), pois, de acordo com o crítico, "Varela não é poeta fácil nem contraditório, apesar de refletir mais de uma tendência; e é injusto inferir que, perdendo-se entre as correntes, nada tenha feito que não continuá-las, sem manifestar uma equação pessoal" (CANDIDO, 1981, p. 257).

Por esse motivo, Candido considera Varela um poeta de transição, que dialoga com tendências românticas imediatamente anteriores ao aparecimento de sua própria poesia, como o indianismo e o byronismo, e que antecipa certa disposição para a crítica social ao voltar-se para questões fulcrais da nação à época, como, por exemplo, a condição do negro, fortemente explorada por Castro Alves alguns anos mais tarde.

De todo modo, ainda que o valor da poesia de Varela seja reconhecido, pois, segundo Candido, há que se considerar a relevância de seu "ímpeto criador", em geral dos melhores do Romantismo (CANDIDO, 1981, p. 257), é fato que hoje o poeta ocupa lugar de pouco destaque na literatura brasileira e a pequena abordagem de sua obra por parte da crítica (há um número diminuto de estudos sobre a produção do autor) é prova cabal disso e revela um certo esquecimento de Varela.

Um comentário de Alfredo Bosi, no entanto, parece instigante e aponta para um viés significativo da poesia do autor, indo ao encontro da abordagem que aqui pretendemos empreender de alguns de seus poemas. Para o crítico e historiador, 
A atração pelo campo, alternada com a mais desbragada boêmia, significa no poeta de Cantos do ermo e da cidade a aversão radical a integrar-se no ritmo da vida em sociedade. A psicologia de fuga levou o eterno adolescente à bebida e à existência errante, o que espelhava a sua incapacidade romântica-decadente de aceitar e, naturalmente, de transformar as pressões do meio (BOSI, 1994, p. 119).

Como mostra o comentário de Bosi, é evidente, em parte significativa dos poemas de Fagundes Varela, a condição de desajuste do sujeito e a oposição entre um mundo ideal almejado, que encontra assento na natureza e na vida simples do campo, e a sociedade civilizada, cuja expressão maior é a cidade.

Sem atentar para questões de ordem biográfica - a bebida, as crises pessoais, o desajuste familiar - com certeza de expressão significativa no autor, pretendemos, nesse estudo, uma leitura da paisagem no poema "As selvas", de Vozes da América, no sentido de mostrar que, nas paisagens criadas, encontra-se mais que um simples espaço, um lugar simplesmente, mas antes uma visão de mundo atravessada por valores individuais e culturais que levam à criação da ideia de um lugar harmônico e acolhedor. Como afirma Fátima Miguez Martins (1994, p. 418), a propósito do tema do exílio e da utopia na literatura romântica,

A natureza, em comunhão com o poeta, é configurada enquanto paisagem destituída de referenciais político-sociais. Na escolha dos elementos naturais que compõem este reino romântico, há sempre um sentimento de ordem e de grandeza que evoca a ideia primitiva da paisagem ideal. É na natureza úbere, útero, seio, mãe.

É essa paisagem abrigo, lar acolhedor, que encontramos no poema "As selvas". Nele, Fagundes Varela (1956, p. 186) dá lugar a uma paisagem ampla e selvagem, que o eu lírico evoca em tom profundamente emotivo e enaltecedor: "Selvas do Novo Mundo, amplos zimbórios/ Mares de sombra e ondas de verdura,/ Povo de Atlantes soberano e mudo/ Em cujos mantos o tufão murmura.".

O poema inicia-se, como se vê, por meio de uma imagem grandiosa, forte e poderosa da natureza selvagem (as selvas) do Novo Mundo, intensamente almejada pelo eu lírico: "minh'alma vos procura embalde" (VARELA, 1956, p. 186). Desse modo, a ideia central do poema está assentada no desajuste do eu diante do mundo que o consome, que o prende e o torna débil, fazendo com que sua alma sofra terrivelmente: "Fere-me os olhos o clarão do mundo,/ Rasgam-me o seio prematuras dores,/ E à mágoa insana que me enluta as noites,/ Declino à campa na estação das flores" (VARELA, 1956, p. 187).

Em oposição ao estado de dilaceramento do sujeito, perdido em meio às ilusões da vida mundana ("o rumor das praças", "os salões dourados"), ao vazio existencial experimentado em um cotidiano em que impera a falsidade ("verme do lodo me desprezam todos"), a dor e a hipocrisia, uma paisagem acolhedora e forte é idealmente construída pelo eu. Ainda que expressões como "Novo Mundo", "Pátria da liberdade" e "Colúmbia terra" tenham um referente preciso, ou seja, a América e, mais especificamente, o Brasil, o poema de Varela não se preocupa com a cor local em primeira instância, com a mera apreciação exótica do ambiente selvagem americano.

$\mathrm{Na}$ verdade, o poema constrói um lugar utópico e a paisagem natural, selvagem, transforma-se em uma grande metáfora, cujo sentido é o de casa, abrigo ontológico, onde o ser desagregado e infeliz em sua realidade cotidiana encontra harmonia, acolhimento e paz: 
E há tanto encanto nas florestas virgens;

Tanta beleza no sertão na sombra;

Tanta harmonia no correr do rio;

Tanta delícia na campestre alfombra;

Que inda pudera reviver de novo,

E entre verduras flutuar minh'alma,

Fanada planta que mendiga apenas

A noite, o orvalho, a viração, a calma! (VARELA, 1956, p. 187).

Desse modo, o mundo natural, de florestas virgens, é concebido e configurado pelo olhar romântico que atravessa todo o poema como uma espécie de jardim do Éden, de paraíso, enfim. Nesse espaço mítico, é possível uma reintegração do homem com ele mesmo e com a natureza, mãe primordial, sempre maior e mais poderosa que o mundo civilizado desestruturante e alienado. Não por um acaso, a estrutura paralelística presente na penúltima estrofe colabora, num crescendo, para a intensificação exclusiva da paisagem natural: o encanto, a beleza, a harmonia e a delícia.

Essas palavras resumem o significado simbólico, místico, dessas florestas virgens, "encantadas", intocadas e, por isso mesmo, autênticas aos olhos do sujeito romântico. Nesse mundo, a reintegração do ser à "casa" é claramente expressa nos últimos versos do poema, em que o eu lírico não se coloca como um simples observador de uma paisagem deslumbrante que se descortina a seus olhos, mas é ele mesmo essa natureza, enquanto a "Fanada planta que mendiga apenas/ A noite, o orvalho, a viração e a calma" (VARELA, 1956, p. 187).

A fusão homem-natureza se completa nesse momento e uma nova realidade se configura, agora de comunhão, totalmente oposta à mundanidade desencantada e dilacerada vivida pelo eu. Na paisagem natural está, portanto, o lugar utópico almejado pelo imaginário romântico, a "Pátria do Ser", a casa-lar, como a descreve Gaston Bachelard (2008). De acordo com Fátima Miguez Martins (1994, p. 418), para o romântico,

\begin{abstract}
A Pátria não é vista enquanto povo, coletividade, mas sim enquanto natureza externa manifestando-se na natureza interna do poeta. $\mathrm{O}$ poeta sente a natureza e dilui-se nesse sentimento.

É o homem mutilado à procura da identidade perdida. E o poeta, peregrino do deserto da existência, essencializa essa volta às origens na sede eterna da ontológica reintegração. $\mathrm{Na}$ perseguição às origens, o gênio inventivo romântico constrói a pátria-quimera, lugar de repouso das insatisfações mundanas.
\end{abstract}

\title{
Sousândrade e a fusão do eu com a natureza
}

A situação de Sousândrade na literatura brasileira, como mostram Augusto e Haroldo de Campos, responsáveis por uma retomada efetiva do autor 60 anos após sua morte, é um caso de silenciamento, de olvido de um "terremoto" que, ao desestabilizar em vários sentidos o padrão de criação literária da época, "produziu uma obra que não teve nem poderia ter o auditório que merecia" (CAMPOS, 2002, p. 23-24), ficando a ele reservada a clandestinidade. 
Espécie de $O$ Guesa, personagem de sua mais importante e inquietante obra, tanto no tocante à vida pessoal atropelada e errante, quanto no fazer poético desconcertante e dissonante para a época - e o autor publica suas Harpas Selvagens em 1857, em pleno Romantismo, portanto -, Sousândrade deixou uma produção singular, antes de tudo moderna, como afirmam os irmãos Campos e outros que dele se ocuparam. A obra do autor, não obstante já contar com estudos importantes e de fôlego, ainda carece de maior atenção por parte da crítica, a qual parece ainda permanecer resistente ao "terremoto" maranhense.

Para Luiz Costa Lima (2002, p. 477), é a modernidade de Sousândrade, que não encontra respaldo no cenário acanhado das letras nacionais, ainda presas a uma mentalidade pautada por aquilo que de mais convencional e acomodado se apresentava no nosso Romantismo, a responsável pela incompreensão e olvido do escritor:

Com efeito, Sousândrade é o único poeta brasileiro que, antes do modernismo, antecipou formas que só depois se desenvolveriam dentro do acervo poético convencional. Só ele não foi mero reflexo de correntes europeias. Por isso mesmo ele se tornou o mais incompreendido dos poetas pré-modernistas.

Para parte significativa da crítica que se ocupou da literatura do poeta maranhense, os irmãos Campos, Luiz Costa Lima, Luísa Lobo, Afonso Ávila, só para mencionar alguns que percorreram ou têm percorrido de forma mais sistemática a produção de Sousândrade, é o caráter inovador, moderno de sua poesia, tanto em relação a questões de ordem formal e estilística, quanto em relação à postura crítica frente a alguns temas e assuntos trazidos por sua poesia que merece maior destaque e que, em verdade, marcaria a diferença do escritor quando comparado a outros autores de seu momento. Nele apresentar-se-ia uma linguagem transfiguradora, não encontrada em seus pares brasileiros.

Entretanto, essa linguagem moderna, transfiguradora, propiciadora de um texto impactante, cuja marca é a ruptura e o choque - não raro permeado de um hermetismo desconcertante -, não desvia o poeta de uma visão de mundo romântica expressa em diversas circunstâncias de sua poesia, inclusive em sua obra-prima, O Guesa.

Nesse sentido, torna-se significativa a observação de Adriano Espínola (2008, p. 33) acerca da forte presença romântica em Sousândrade, principalmente nas obras iniciais:

Vale lembrar, por outro lado, que numerosos poemas de Harpas Selvagens e de Eólias não apresentam obscuridade, escritos que foram dentro do cânone romântico, em que o escritor, de um modo geral, expressa o seu eu lírico atormentado, louva a natureza, a pátria, a região e se volta, amoroso, para musas reais e/ou imaginárias. Neles, utiliza com maestria formas predominantes da época e linguagem transparente, bastante comunicativa, mas nunca superficial.

É próxima também a visão de Luiz Costa Lima, para quem Sousândrade, sobretudo no tratamento dado à natureza, consegue pouco êxito no tocante à criação de uma linguagem singular, dominando a "empostação romântica" (LIMA, 2002). No entanto, apesar dessa "empostação romântica", vista pelo crítico como uma inferioridade da poesia de Sousândrade, Costa Lima não deixa de observar a excepcionalidade do escritor mesmo em terreno (o da natureza) no qual menos se afastou dos 
convencionalismos românticos, ao afirmar que, "Em um caso, todavia, pelo menos, o poeta conseguiu excepcionalmente a ideia das correspondências: a existente entre o destino do homem e o sentido das coisas da natureza" (LIMA, 2002, p. 488).

É numa certa proximidade com essas colocações acerca da figuração da natureza em Sousândrade que pretendemos abordar o poema "Inverno", de Harpas Selvagens, primeira obra do autor, publicada em 1856. "Inverno" parece caminhar em direção semelhante àquela que encontramos no poema "As selvas", de Fagundes Varela, pois à paisagem natural é concedido o estatuto de um mundo encantado, regido por uma harmonia própria, que se nem sempre presa aos eflúvios da beleza e da doçura, posto que tomada por estados de assombro, como a tempestade, por exemplo, conforma-se como um livro aberto a ser decifrado e que funciona "como o traje feito sob medida para o homem" (LIMA, 2002, p. 488).

Em "Inverno", de início, uma questão parece se fazer ao mesmo tempo reveladora daquela "empostação romântica" da qual fala Luiz Costa Lima, no caso, a paixão pela natureza, presente em Varela, como visto, e em praticamente todos os nossos românticos, com um certo distanciamento, um olhar singular para essa mesma natureza quando o poeta foge do lugar comum ao falar sobre esse espaço-tempo no qual é transformado o inverno.

No poema, há uma fuga do sentido normalmente relacionado a essa estação do ano, envolta por uma atmosfera fria, triste, sombria, sem vida, que caracteriza o inverno no hemisfério norte. Na contramão dessa imagem, e situando-se dentro de um contexto tropical, o poema de Sousândrade mostra a complexidade e a indissolúvel ambiguidade a caracterizar a essência do inverno equatorial:

Salve! Felicidade melancólica,

Doce estação da sombra e dos amores -

Eu amo o inverno do equador brilhante!

A terra me parece mais sensível. (ANDRADE, 2002, p. 136).

É no paradoxo sustentado pela expressão "felicidade melancólica", que se desdobra na "estação da sombra e dos amores", que a natureza passa a ser vista como uma paisagem dinâmica, em um movimento indelevelmente contraditório, a sustentar, ao mesmo tempo, a felicidade e a melancolia, a sombra e os amores, o sol e a chuva, a tranquilidade e a tempestade, o dia e a noite.

Assim, o inverno descrito por Sousândrade é cheio de cor, vida e movimento, este ora tranquilo, ora tormentoso. De início, é a imagem de uma natureza invernal acolhedora que se desenha aos olhos do leitor, por meio de uma percepção toda positiva que dela tem o eu lírico:

Eu amo o inverno do equador brilhante!

A terra me parece mais sensível.

Aqui as virgens não se despem negras

À voz do outono desdenhoso e déspota,

Ai delas fossem irmãs, filhas dos homens!

Aqui dos montes não nos foge o trono

Dessas aves perdidas, nem do prado

Desaparece a flor. A cobra mansa,

Cor d'azougue, tardia, umbrosa e dúctil, 
No marfim do caminho endurecido

Serpenteia, como ondas de cabelos

Da formosura no ombro. À noite a lua,

Qual minha amante d'inocente riso

Co'a face branca assenta-se nas palmas

Da montanha estendendo os seus candores,

Mãe da poesia, solitária, errante:

O sol nem queima o céu como os desertos,

Simpáticas manhãs é sempre o dia. (ANDRADE, 2002, p. 136).

A posição do eu diante da paisagem descortinada a sua frente, "Eu amo o inverno", é fundamental para o sentido positivo que o inverno, enquanto tempo e espaço, terá para o sujeito lírico, refletido nas imagens de caráter acolhedor com que descreve a natureza. Em tudo há vida e beleza: nas virgens que não sucumbem à aspereza negra do outono; nos animais (ave, cobra), que continuam sua movimentação cotidiana; na noite, cuja lua abençoada, comparada a uma amante encantadora, ilumina a escuridão; no sol, fonte de vida e luz, jamais castigante, mas ameno e aconchegante.

O posicionamento romântico, já apontado em Fagundes Varela, aparece também em Sousândrade em uma paisagem invernal, cujo sentido está próximo daquela naturezamãe, abrigo protetor. Por esse motivo, o eu lírico insiste no amor que sente pelo inverno: "Eu amo o inverno".

O movimento encantado da natureza, capaz de prender o eu ao sentimento amoroso, não se esgota nas paisagens amenas, de beleza, doçura e luminosidade, inclusive à noite, com a bela madrugada, "Linda menina a amanhecer na fonte" (ANDRADE, 2002, p. 139), mas também quando do quadro natural emerge uma paisagem mais tormentosa, dominada pela tempestade, pela chuva, pelos raios e pelos trovões:

Doida acorda a avezinha que dormia,

Anjo da tempestade, ela a conhece,

E começa a gritar voando inquieta:

Os ramos fervem: fogem se abrigando

Pelas barreiras os jovens trovadores;

E ela só tempera-se estridente

D'ígneos carmes! O cedro range e os montes,

E entre os polos vanzeia a tempestade:

Vai lançada tinindo pelas nuvens

Contra os trovões que se arrebentam; guincha

Seguindo o raio, e, no cruzar dos ares,

Das asas solta elétricas faíscas! (ANDRADE, 2002, p. 139)

A dimensão grandiosa da natureza se mantém nessa outra passagem, um tanto avessa às outras anteriormente apresentadas no poema no tocante à serenidade predominante, quer de uma "mata silenciosa/onde suspira a nambu-preta, e canta/Salmos o sabiá d'íntimas harpas" (ANDRADE, 2002, p. 138), quer do calor do sol equatorial e invernal, "que nem queima o céu como os desertos", sendo o dia sempre "simpáticas manhãs" (p. 136).

A longa estrofe final que compõe "Inverno" apresenta um momento de fúria da natureza e é composta por um conjunto de procedimentos semânticos, sonoros e lexicais 
que colaboram para a criação de uma paisagem muito mais tormentosa e violenta, distante das paisagens anteriores, cujos elementos recobriam-se de leveza.

Um passeio rápido pelos verbos é suficiente, de início, para comprovar a mudança e o novo cenário apresentado. Gritar, ferver, fugir, ranger, vanzear, tinir, arrebentar, guinchar, fazem parte também da vida natural, mais furiosa, mas igualmente grandiosa para um eu que nela se reconhece:

E entre os polos vanzeia a tempestade:

Como ela, também preso os balanços

Do vendaval furioso e do relâmpago,

E minha alma agitar na voz dos céus.

Eu amo o inverno! Aqui durmo de amores,

Redobrando a galharda seriquara

Nos bamburrais do rio; a espreguiçar-se

Na montanha a palmeira ao doce fluido

Do áureo dedo do sol, dourada fềnix

A renascer-se da cinérea noite -

Ou minh'alma agitando à voz dos céus. (ANDRADE, 2002, p. 140).

Está posta, dessa maneira, a comunhão do eu com a natureza, aspecto tipicamente romântico e que na poesia de Sousândrade parece alcançar uma dimensão ontológica. A paisagem natural não apenas reflete os estados de alma do sujeito, numa sintonia com os sentimentos do indivíduo. Eu e natureza não se separam, mas são uma única e mesma coisa. Não há distanciamento entre o eu e a paisagem, pois não se encontra fora da paisagem descrita, mas dentro, é parte dela no sentido mais profundo de sua participação e nela reconhece o fundamento complexo e contraditório de seu ser, a embalar-se nos amores, cantos e brilhos da natureza acolhedora - "Eu amo o inverno! Aqui durmo de amores" (ANDRADE, 2002, p. 140) -, e em seus mais tempestuosos estados, "Como ela, também prezo os balanços/Do vendaval furioso e do relâmpago" (p. 139).

Portanto, a paisagem natural expressa, simbolicamente, a complexidade do ser ao revelar sua essência nos movimentos/estados contraditórios que a conformam. Daí aquela "felicidade sombria" de que fala o poema, paradoxo que põe em cena o fundamento contraditório e ambíguo da natureza e do homem.

\section{Conclusão}

Tanto em "As selvas", de Varela, quanto em "Inverno", de Sousândrade, parece ser possível afirmar com Michel Collot (2013, p. 83) que

A correspondência que o Romantismo instaura entre a paisagem e o estado d'alma tem sentido duplo: supõe não somente a projeção da afetividade sobre o mundo, mas também a repercussão deste sobre a consciência do sujeito. "As paisagens eram como um arco que brincavam com a minha alma", confidencia Stendhal. Ao invés de enclausurar o sujeito na interioridade, faz com que ele se abra às influências do exterior: "Minha alma se esparrama sobre o que vê", escreve Maurice de Guérin; "ela se transforma como os horizontes e toma suas formas". 
"Traje sob medida feito para o homem" (LIMA, 2002, p. 488), a natureza revelase como esse livro aberto que permite ao sujeito nela encontrar e satisfazer os seus mais intensos desejos utópicos de abrigo e comunhão, claro em Varela, e como a compreensão de si mesmo enquanto natureza misteriosa e complexa, como em Sousândrade. Em ambos os casos, a busca parece ser a de um reencantamento do mundo a partir da criação de uma "terra natal", lugar primordial de pertencimento, abrigo ontológico. Fica evidente, nesse sentido, a estilização da natureza e da vida em meio à natureza, transformada, como mostra Norbert Mecklenburg (2013, p. 189) a propósito de certo regionalismo romântico, em "uma esfera de felicidade, isolada como uma ilha, afastada das contradições, dos conflitos e das ameaças do mundo sócio-histórico". Nesse "idílio", a tão sonhada comunhão, buscada ardentemente pela arte romântica, parece ser possível.

\section{REFERÊNCIAS}

ANDRADE, J. de S. Inverno. In: CAMPOS, A.; CAMPOS, H. Revisão de Sousândrade. 3. ed. São Paulo: Perspectiva, 2002.

BACHELARD, G. A poética do espaço. Tradução de Antônio de Pádua Danesi. 2. ed. São Paulo: Martins Fontes, 2008.

BERQUE, A. El pensamiento paisajero. Tradução de Maysi Veuthey. Madri: Biblioteca Nueva, 2009.

BOSI, A. História concisa da literatura brasileira. 34. ed. São Paulo: Ática, 1994.

CAMPOS, A.; CAMPOS, H. Re-visão de Sousândrade. 3. ed. São Paulo: Perspectiva, 2002.

CANDIDO, A. Formação da literatura Brasileira. 6. ed. Belo Horizonte: Itatiaia, 1981. v. 2.

COLlOT, M. Paysage et poésie: Du romantisme à nos jours. Paris: José Corti, 2005.

Poética e filosofia da paisagem. Tradução de Ida Alves et al. Rio de Janeiro: Oficina Raquel, 2013.

ESPÍNOLA, A. O irisado Sousândrade. In: ANDRADE, J. de S. Melhores poemas. São Paulo: Global, 2008.

LIMA, L. C. O campo visual de uma experiência antecipadora: Sousândrade. In: CAMPOS, A.; CAMPOS, H. Re-visão de Sousândrade. 3. ed. São Paulo: Perspectiva, 2002.

LÖWY, M.; SAYRE, R. Revolta e Melancolia. O romantismo na contramão da modernidade. Rio de Janeiro: Vozes, 1995.

MARTINS, F. M. Utopias do exílio romântico. In: MEIBY, J. C. S. B. América: Ficção e utopias. São Paulo: EDUSP, 1994.

MECKLENBURG, N. Regionalismo literário em tempos de globalização. In: ARENDT, J. C.; NEUMANN, G. R. (Org.). Regionalismus - regionalismo: subsídios para um novo debate. Caxias do Sul: EDUCS, 2013.

ROUSSEAU, J.-J. Os devaneios do caminhante solitário. Tradução de Júlia Rosa Simões. Porto Alegre: L\&PM, 2008. 
SECCHIN, C. A. Poemas de oito faces. In: VARELA, L. N. F. Melhores poemas. São Paulo: Global, 2005.

VARELA, L. N. F. Poesias completas. São Paulo: Saraiva, 1956.

Recebido em: 02/09/2016

Aprovado em: 29/11/2016 